\title{
Notes on the vocalizations of Silver-eared Mesia (Mesia argentauris)
}

Peter Boesman

In the following we briefly analyze and compare voice of the different races of Silver-eared Mesia (Mesia argentauris). We also try to quantify the extent of any vocal differences using the criteria proposed by Tobias et al. (2010), as a support for taxonomic review.

We have made use of sound recordings available on-line from Xeno Canto (XC) and Macaulay Library (ML).

Our main interest is to compare Sumatran birds with races from the mainland. We have found only a single recording of song from Sumatra:

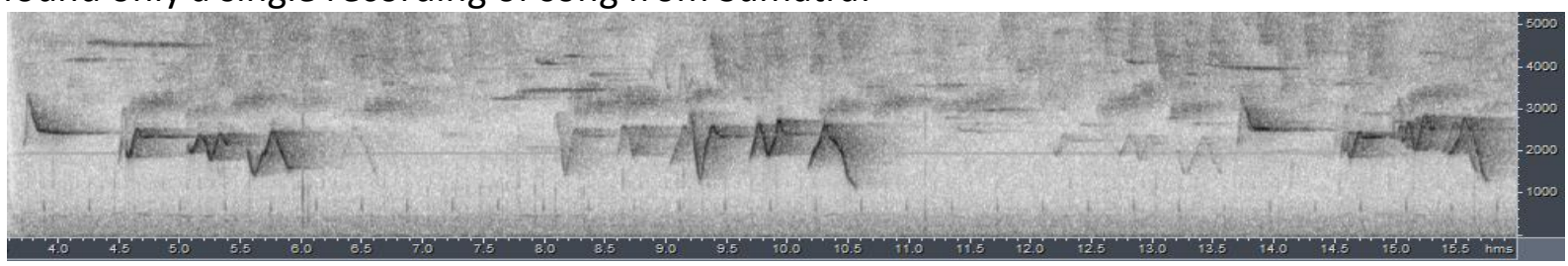

Song apparently a single downslurred whistle (highest in pitch, reaching about $3-3.2 \mathrm{kHz}$ ) followed by 3 more complex whistles. Last whistle reaching lowest pitch (down to 1150$1250 \mathrm{~Hz}$ ), with slight variations.

To be compared with songs from the mainland slightly(examples from the entire distributional range):

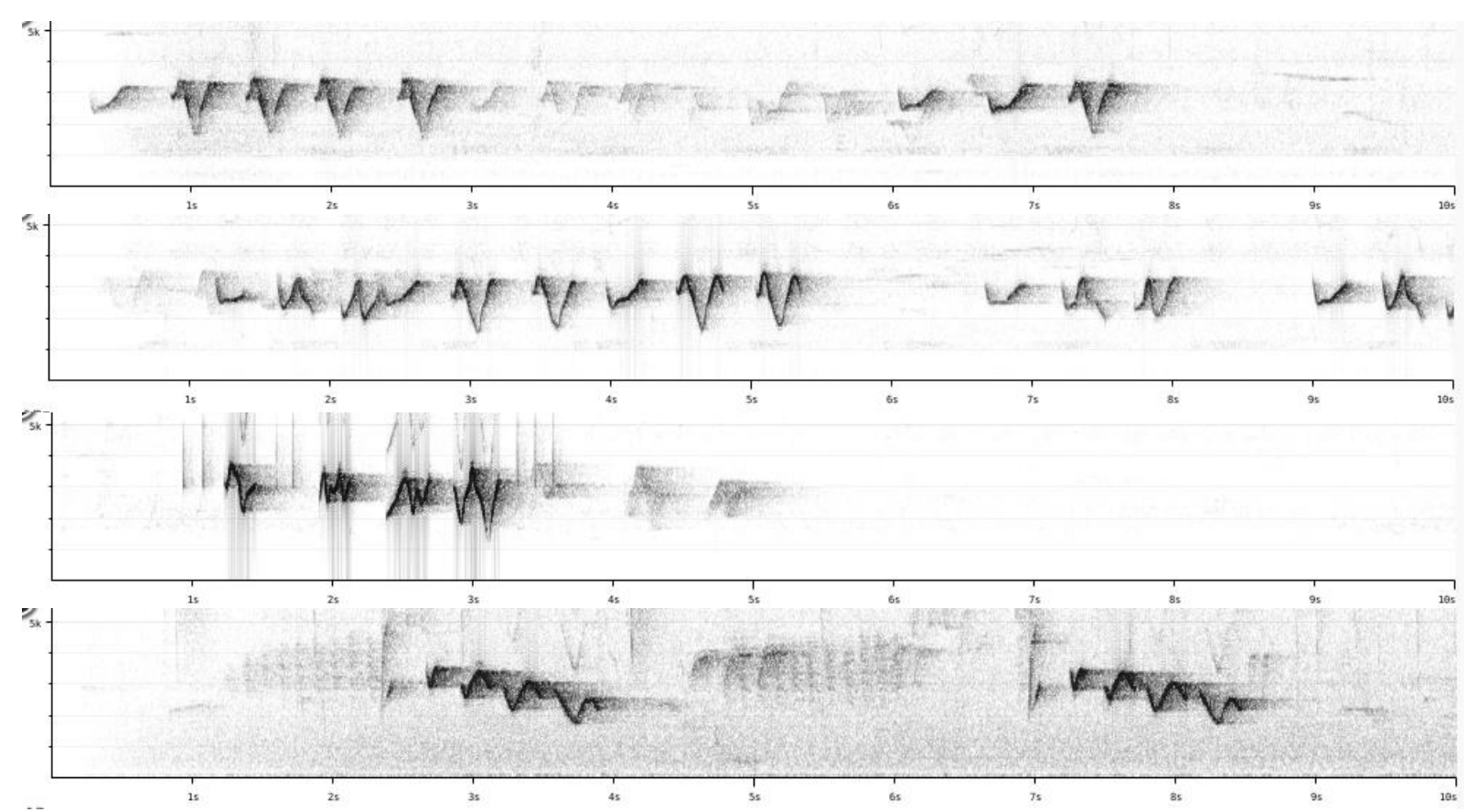



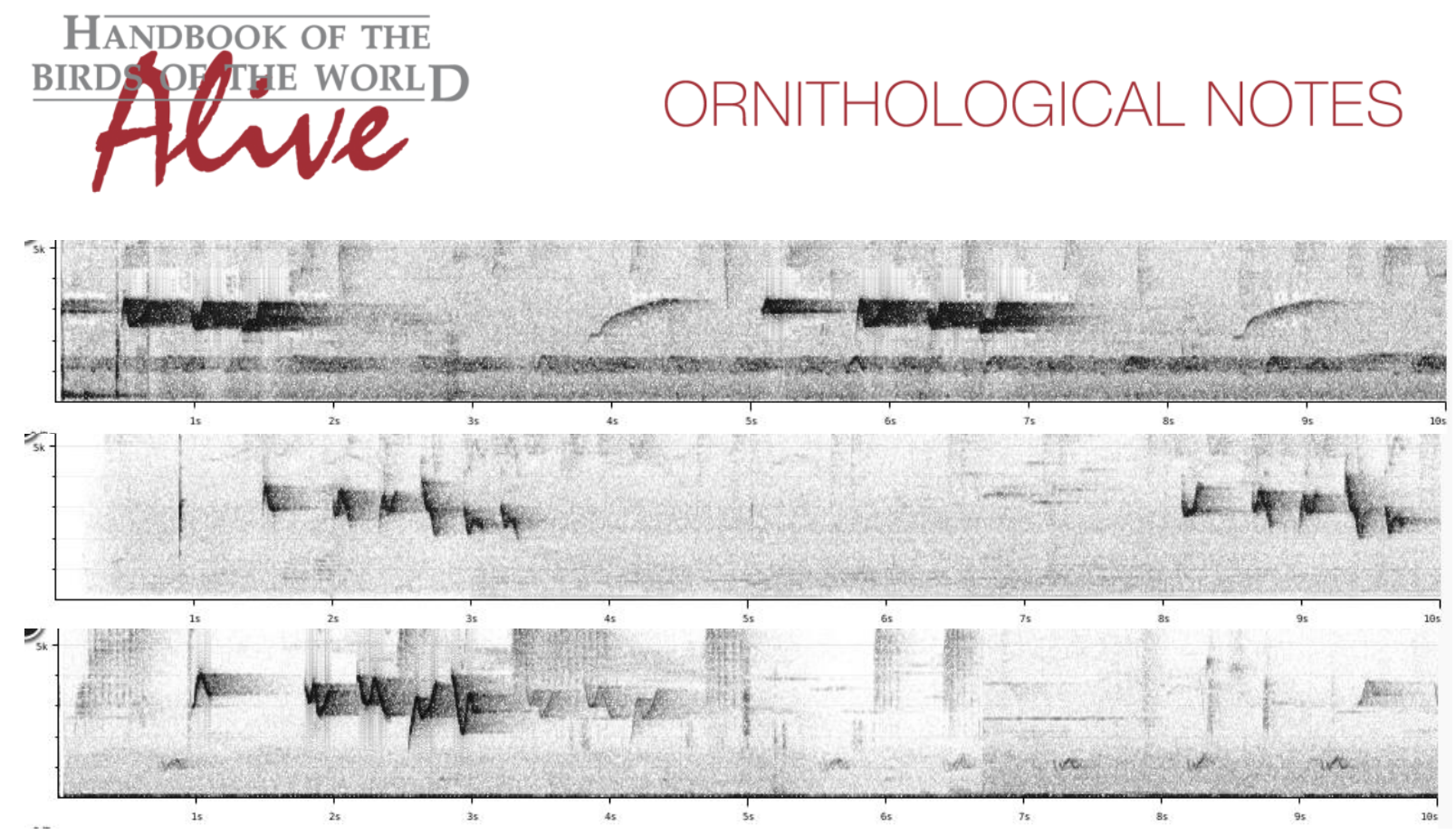

It would seem that birds from the mainland usually don't reach as low a frequency (typically above $1500 \mathrm{~Hz}$ ). Other parameters, including note shape show quite some variability, and as a result the Sumatran recording falls well within the range of variability of the other races.

With only one example from Sumatra, one can't draw firm conclusions. At most, there is an indication that notes seem to reach lower frequencies.

This note was finalized on 13th April 2016, using sound recordings available on-line at that moment. We would like to thank in particular the many sound recordists who placed their recordings for this species on XC and ML.

\section{References}

Tobias, J.A., Seddon, N., Spottiswoode, C.N., Pilgrim, J.D., Fishpool, L.D.C. \& Collar, N.J. (2010). Quantitative criteria for species delimitation. Ibis 152(4): 724-746.

\section{Recommended citation}

Boesman, P. (2016). Notes on the vocalizations of Silver-eared Mesia (Mesia argentauris). HBW Alive Ornithological Note 277. In: Handbook of the Birds of the World Alive. Lynx Edicions, Barcelona. (retrieved from http://www.hbw.com/node/1251718 on 8 October 2016). 